УДК 94(470): 321

Вячеслав НИКОНОВ

\title{
РОССИЙСКАЯ МАТРИЦА
}

Что отличает Россию от других стран? Одни скажут: соборность, коллективизм, “самодержавие, православие, народность”, природный демократизм. Другие - органичный авторитаризм, имперская диктатура, всевластие государства и бесправие общества, вспомнят известные строки Владимира Гиляровского о двух напастях: “Внизу власть тьмы, а наверху тьма власти”. Всё это правда. И всё - неправда.

Россия - совершенно не однозначный феномен, который плохо понимают не только иностранцы, но и всю жизнь прожившие в ней люди. Николай Гоголь поражался в 1845 году, насколько современники не могли или не хотели постигать свою страну: "Велико незнание России посреди России. Всё живёт в иностранных журналах и газетах, а не в земле своей” [Гоголь, 1952: 308]. Или Россия непознаваема?

Очевидно, что недостаточно просто констатировать своё непонимание России, восторгаться её величием или возмущаться её недоделанностью. Россию можно понять, если постараться узнать: каковы наши особенности, откуда они и насколько они специфичны; на каком свете мы находимся по основным параметрам; какое место занимаем в соотношении с основными центрами силы и в отношениях с ними?

Можно ли говорить об одной российской матрице? Разве можно найти что-то общее между современной Россией и обществом, скажем, Киевской Руси?

Фёдор Тютчев был прав, когда уверял, что должность русского Бога - не синекура. Однако, вопреки расхожим стереотипам, исторически Россия - крепкое, жизнеспособное и стабильное государство. Одно из двух-трёх на планете, которые могут похвастаться пятью веками непрерывного суверенного существования, не прерванного завоеваниями извне или нахождением под чьей-то властью.

За свою более чем тысячелетнюю историю Россия четыре раза терпела подлинные Крушения, когда вставал вопрос о выживании её как государства и нации. Первое Крушение было вызвано внешним завоеванием: в XIII веке раздробленные русские княжества стали добычей монгольского войска. Все последующие Крушения объяснялись почти исключительно внутренними причинами, которые порождали революционные взрывы, ставившие страну на грань существования. Так было в начале XVII века, когда Россия захлебнулась в братоубийственной Смуте. Так было после революции 1917 года, когда гражданская война унесла миллионы жизней, а государственность была восстановлена методами большевистской диктату-

(C) Никонов Вячеслав Алексеевич, доктор исторических наук, профессор, декан факультета государственного управления МГУ. Адрес: 119991, Россия, Москва, Ленинские горы, д. 1. E-mail: ieras@mail.ru

Ключевые слова: цивилизации, Россия, русская культура, европейская цивилизация, демократия, коллективизм.

DOI: http://dx.doi.org/10.15211/soveurope22015919 
ры. Так было в 1991 году, который принёс развал СССР (который был формой существования России). Четыре Крушения, которые Ахиезер, Клямкин и Яковенко назвали “катастрофами российской истории", эти авторы связали с последовательной гибелью киевской, московской, романовской и советской государственности [Ахиезер, Клямкин, Яковенко: 2005].

После каждого из этих Крушений Россия возрождалась, начинала заново. Каждый раз это была другая Россия. Но только немного другая. Потому что люди оставались теми же, и они воспроизводили во многом прежние ментальные культурные стереотипы. И здесь мы как раз не оригинальны. Элементы разрыва, моменты крушений встречались у всех наций и государств, причём, даже чаще, чем в России. Но они не теряли своего лица, своей матрицы. Если, конечно, вообще не исчезали с лица Земли. Генетический код нашего общества оставался во многом неизменным.

Россий, если можно так выразиться, много. Существует очень большой плюрализм этносов, идеологий, географических зон. Но Россия одна как цельный (или цельный именно в своей плюралистичности) организм. В его основе лежит цивилизационный, культурный генетический код, закладывающий основу общей российской матрицы. "Россия не есть пустое вместилище, в которое можно механически, по произволу, вложить всё что угодно, не считаясь с законами её духовного организма. Россия есть живая духовная система со своими историческими дарами и заданиями. Мало того, - за нею стоит некий божественный исторический замысел, от которого мы не смеем отказаться и от которого нам и не удалось бы отречься, если бы мы даже того и захотели... Каждый народ творит то, что он может, исходя из того, что ему дано. Но плох тот народ, который не видит того, что именно дано именно ему, и потому ходит побираться под чужими окнами" [Ильин, 1992: 327], подчёркивал философ Иван Ильин.

Для многих аналитиков зависимость настоящего от исторического пути - не больше, чем метафора, из которой может, в лучшем случае, следовать вывод о необходимости учиться на ошибках истории. Для других сама эта идея кажется весьма опасной, если не реакционной, призывающей мириться с неэффективными институтами, отсталостью и безобразиями под предлогом некоей заданности этих явлений изначальным историческим кодом. Но для множества серьёзнейших людей во всем мире культурная матрица различных стран, народов и цивилизаций является предметом тщательного анализа. Потому что это тот фундамент, на котором предстоит строить будущее.

Главный фактор, определяющий судьбу России - это самая северная и самая холодная страна в мире. Две трети её территории покрыты снегом две трети года. "Боковая ветвь православно-христианской цивилизации в России подверглась вызову лесов, дождей и морозов, ещё более суровому, чем тот, с которым пришлось бороться западной цивилизации" [Тойнби, 2009: 182], - подчёркивал Тойнби.

Такое местоположение имело позитивные аспекты. Суровая зима предохраняла Россию от тропических болезней, которые опустошали другие части земного шара. Северные леса были богаты зверем, а на меха в мире всегда существовал большой спрос; они давали древесину, из которой на протяжении веков была выстроена почти вся российская недвижимость, создавался флот. Леса хоть немного защищали от кочевников. Но размеры и климат страны брали свой дополнительный налог с любой деятельности.

Леса и болота создавали на каждом шагу множество непредвиденных опасностей. Это приучало внимательно следить за природой, развивало осторожность и изворотливость в трудных обстоятельствах, привычку к терпеливому преодолению невзгод и лишений. "В Европе нет народа менее избалованного и притязательного, 
приученного меньше ждать от природы и судьбы и более выносливого" [Ключевский, 1987: 312], - подчёркивал Василий Ключевский.

Колонизация, которая, как мы увидим, была далеко не только процессом поиска новых плодородных земель, предопределила размеры России, охватившей в итоге 11 часовых поясов (хотя официально сегодня осталось только девять), что тоже стало важнейшим компонентом российской матрицы, наложило отпечаток на все аспекты существования страны. "Пейзаж русской души соответствует пейзажу русской земли, та же безграничность, бесформенность, устремленность в бесконечность, широта" [Бердяев, 1990: 8], - утверждал Николай Бердяев.

Европу во многом сделала торговля. Центральная Россия удалена не только от основных европейски торговых путей - морских и атлантических, но и от традиционных материковых, по которым осуществлялись коммерческие связи Европы с Азией. Огромные расстояния, климат делали и сухопутные коммуникации невозможными в течение значительной части года. Основными географическими доминантами выступали реки (по объемам протекающей по её территории пресной воды Россия уступает только Бразилии), которые определяли и пути миграции, и пределы государства. Российская цивилизация была речной. Реки указывали завоевателям, где искать населенные пункты русских, которые размещались по берегам рек. Территория России всегда была исключительно уязвима для завоеваний.

Величайший военный стратег Карл фон Клаузевиц, в 1812 году служивший в русской армии отмечал, что стратегически Россия не защитима. Клаузевиц считал, что Россию спасало то обстоятельство, что из-за мороза в ней мало кому хотелось задерживаться, а тем более жить. И пространство. "Русское государство так велико, что позволяет играть в “кошки-мышки” с неприятельской армией; на этом и должна базироваться в основном идея её обороны против превосходных сил неприятеля. Отступление в глубь страны завлекает туда же неприятельскую армию, оставляя в её тылу обширные пространства, которые они занять не в состоянии" [Клаузевиц, 1937: 93-94, 92]. Так будут поступать и Пётр I в войне со шведами, и Александр I, и Сталин, противостоявшие вооруженным силам большинства континентальных европейских государств, которые привели Наполеон и Гитлер.

Сложнее обстояло дело с южными рубежами, где на равнинах, тянущихся от Монголии до Карпат, с VII века до н. э. до XVIII века нашей эры безраздельно властвовали воинственные кочевые племена. Долгое время Великая Степь являлась определяющим фактором и российской истории. Бродель подчёркивал: “Если орды кочевников устремлялись в сторону Ирана, Багдада, то для русских это была удача, это означало, что угроза прошла стороной... Судьба России долгое время была предопределена её приграничным положением: защищая Европу, она амортизировала удары, которые наносились со стороны Азии, что дорого ей обходилось" [Бродель, 2008: 502]. Именно благодаря этому обстоятельству Европа была во многом избавлена от ударов Степи, которые гасились Россией. Но в истории средневековой Руси можно насчитать лишь не более двух с небольшим десятилетий - время княжения Ярослава Мудрого и начало правления его сыновей, - когда она не испытывала прямой угрозы с юга. И это были годы настоящего расцвета Киевской Руси.

Западноевропейский король мог жить в своем загородном дворце, а его герцоги в своих загородных замках, предоставив городскому населению вольности, потому что самыми опасными врагами для них мог быть соседний король или герцог, a caмой большой угрозой - выплата налогов ему. Русские князья и их дружинники не могли жить в отдельных дворцах и замках, их бы сразу по одиночке поубивали степняки. Русские "короли и герцоги" вынуждены были жить в укрепленных городах, все население которых должно было не просто заниматься торговлей и ремес- 
лами, а быть готовым взойти на крепостную стену, чтобы с оружием в руках защищать жизни свои и собственных семей. Альтернативой этому было либо смерть, либо рабство. И горожане были организованы не по цехам и гильдиям, как в Западной Европе, а как на войне - по сотням и тысячам.

Необходимость обеспечивать выживание и обороноспособность большой территории, находящейся в сложном геополитическом окружении, предполагала мобилизацию и перераспределение ресурсов от исключительно бедного и весьма немногочисленного населения. Это, в первую очередь, привело к высокой степени централизации власти. Таким образом, доминировавший на протяжении большей части российской истории тип государственности был продиктован поиском оптимальной организации управления и выживания в крайне сложных климатических и географических условиях, опасном геополитическом окружении при исключительно слабых материальных основах общества и бедности населения.

Матрицу традиционной российской государственности можно определить, как сословно- (профессионально- и национально-) территориально-представительную автократию с сильным самоуправлением и чувством индивидуальной свободы человека.

Для российской политической культуры - как дореволюционной, так и послереволюционной - характерна, в первую очередь, ярко выраженная этатистская ориентация. Государство - это не “ночной сторож” и не механизм управления, основанный на принципе “общественного договора”, для реализации которого граждане отказываются от части своего естественного суверенитета. Государство нередко понимается как полный синоним понятиям Россия или Отечество. "В России государство воспринимается как становой хребет цивилизации, гарант целостности существования общества, устроитель жизни, в том числе, экономической. Такое воспитание отражало, пусть в несколько гипертрофированной форме, реальную роль государства в стране со специфическими геополитическими, географическими условиями и отсутствием гражданского общества" [Баталов, 2002: 17], - подчёркивал политолог Эдуард Баталов.

В российской модели, как и в западной, наблюдались элементы общественнополитического плюрализма, однако многие из западных факторов и институтов действовали слабее или не действовали вообще. По степени плюрализма Киевская Русь, где князь, княжеская (боярская) дума и вече были неотъемлемыми компонентами системы управления, ничем не уступала Западной Европе, если не превосходила её. В то же время, в Древней Руси и Московском государстве отношения между монархом и его вассалами не оформлялись в договорном порядке, значимых усилий законодательным путём ограничить прерогативы верховной власти не предпринималось. Совокупность этих черт определяло отсутствие в России реального разделения властей на исполнительную, законодательную и судебную, их функции неизменно были переплетены. Верховная власть в России - после прекращения созыва Земских соборов и Боярской думы - была неразделенной. "Порядок - от Царя”, спасать и строить страну способна только верховная власть, "горе тому царству, коим владеют многие”, “лучше грозный царь, чем семибоярщина”. В императорской России права государственной власти в полном объеме принадлежали Государю Императору (до Ocновных законов 1906 года, которые создавали представительные органы). В СССР Советы воплощали в себе идею соединения исполнительной и законодательной властей. В современной России по Конституции 1993 года существует институт очень сильной президентской власти, поставленной над системой разделения властей.

В числе отличительных свойств российской системы власти - её неинституционализированность и персонификация. Важны не столько институты власти, сколько люди у власти. Академик Юрий Пивоваров подчёркивал, что “это Власть всегда 
персонифицирована, т.е. обязательно предполагает определённого её носителя (в отличие от этого на Западе власть имеет абстрактную природу - отделена, независима от правителя, не является его личной прерогативой)" [Пивоваров, 2006: 17]. В России верховным правителям прощали все. Кроме слабости. Правитель, воспринимавшийся как слабый, мог столкнуться с крайними формами протеста. Характерны в этом смысле судьбы Николая II и Михаила Горбачёва.

Вместе с тем, мнение о всемогуществе во все времена самодержавной российской власти не следует абсолютизировать. Даже в эпоху абсолютизма (XVIII-XIX века) способность монархов по своему усмотрению строить жизнь страны, реформировать её были весьма ограниченны: их прерогативы сдерживались наличием традиции, влиятельной бюрократии, императорской семьи, дворянского землевладения, армейской верхушки, перспективами возможных дворцовых переворотов и народных бунтов.

Система управления во все времена не отличалась четкостью, функции различных государственных органов традиционно были переплетены и запутаны. Привычка, которую Ключевский называл наследственной, "к административным боковушам, клетям и подклетям" прошла в неизменном виде - от домостроительных привычек московских правителей до сегодняшнего дня. Власть никогда не была полностью формализованной, существовало несоответствие между реальной и предусмотренной законом процедурами принятия решений. Российской традицией стало существование узкого внеинституционального круга лиц, которые на практике подменяли собой формальные государственные институты. Этот круг принимал форма Ближней думы, Избранной рады, Тайного совета, Негласного совета, узкого круга Политбюро, малого Совнаркома, “семьи” Бориса Ельцина и т.д.

Родовой чертой российской государственности можно считать разделение верховной власти, которая концентрировалась в руках князя, царя, императора, Генерального секретаря ЦК КПСС, президента, и высшей исполнительной власти, находившейся в руках высшей бюрократии - Боярской думы, Сената, Государственного совета, Совета министров, Совнаркома, Правительства. При этом в руках верховной власти неизменно оставался контроль над армией, спецслужбами и дипломатической службой.

Россия на протяжении большей части своей истории располагала системой представительных органов - вече, Земские соборы, Государственная дума, Верховный Совет. В период после заката веча, которое представляло так или иначе всё население отдельных городов и прилегающих к ним местностей, представительство носило сословный и территориальный характер. Представительные (законодательные) органы в России были, за редким исключением - не столько противовесом, сколько продолжением верховной власти, её подспорьем, и именно власть в решающей степени определяла их повестку дня.

Русская система права изначально - через первые судебники Киевской Руси была связана с византийскими номоканонами, включавшими и церковные правила, и гражданское законодательство, а через них - с системой римского права. Судебные функции длительное время принадлежали исполнительной власти, но на региональном и местном уровнях издревле существовали выборные судебные органы. Кодификация законов неизменно оставалась слабым местом, противоречия между различными законодательными нормами были в порядке вещей. Закон часто противопоставляется правде как высшей справедливости, велика снисходительность к правонарушителям.

Государство выступает единым пространством власти, которая распространяется иерархически. Наделение властными полномочиями идет с высших ярусов 
иерархии к низшим, вертикальные связи оказываются важнее горизонтальных или сетевых. На уровне территорий эта неразделённость власти тоже очевидна. Маятник постоянно качался между стремлением все решать из столицы с помощью органов центрального правительства и созданием относительно самостоятельных органов местного управления и самоуправления.

Губное и земское самоуправление существовало на протяжении веков. Однако суженные права выборного представительства в городах, где - особенно на южных и восточных рубежах - большую роль играли служилые люди (стрельцы, казаки, пушкари), не позволяло городам выступать флагманами капиталистических отношений. Экспериментируя с западными методами городского управления и самоуправления, Россия до 1930-х годов даже близко не приближалась к западному уровню урбанизации. Российская цивилизация была деревенской и ментально во многом продолжает оставаться таковой, что ныне подтверждается наличием беспрецедентного для остального мира числа дач и приусадебных хозяйств.

Русская колонизация по многим аспектам напоминала западную, и русские служилые люди и колонисты не были ангелами. Но россияне не уничтожили ни одной цивилизации, как испанцы поступили с ацтеками и инками; жертвы их колонизаторской деятельности не измерялись десятками миллионов человек, как в случаe с западной колонизацией. Российские власти оставили аборигенов в местах обычного проживания, а не согнали в резервации и не уничтожили, как в Соединённых Штатах. Не стали обращать новых подданных в рабов и заниматься их торговлей в глобальном масштабе, как это делали европейские колониальные державы.

Британский журналист и писатель М. Уоллес писал в XIX веке: “Русский крестьянин точно создан для мирной, земледельческой колонизации. Среди нецивилизованных племён он добродушен, вынослив, миролюбив, способен терпеть крайний недостаток и отлично умеет приноравливаться к обстоятельствам. У него в характере вовсе нет высокомерного сознания личного и национального превосходства и непреодолимого стремления к господству, которое часто превращает преклоняющихся перед законом, свободолюбивых британцев в жестоких тиранов, когда они приходят в соприкосновение с более слабой расой. У него нет желания управлять, и он вовсе не хочет обратить туземцев в дровосеков и водовозов" [Размышления о России и русских, 1996: 124].

Получили широкое распространение смешанные браки. Нередко в местах колонизации образовалась единая синкретичная культура, когда русские перенимали кухню, одежду или даже язык и элементы верований (шаманства, анимизма) местных жителей. "При российской примирительной внутренней политике присоединенные народы занимали свое органичное место в едином государстве, сохраняли свое физическое бытие, природное окружение, религию, культуру, самобытность" [Солженицын, 1998: 112], - подчёркивал Нобелевский лауреат Александр Солженицын.

Система управления нерусскими областями отличалась сочетанием максимально допустимого сохранения местных особенностей и жизненных устоев, невмешательства чиновников в сферы, регулируемые традицией и обычаями. Для всех жителей существовала общая правовая среда, которая если и отличалась для отдельных территорий и народов, то только в лучшую сторону (за исключением, пожалуй, лишь “черты оседлости” для евреев). Окраинные территории чаще всего и не могли быть источником обогащения, коль скоро большая часть империи была либо совершенно не рентабельна даже для проживания в силу климатических условий, либо сильно отставала в развитии от центра, который выступал источником инвестиций, а не наоборот. Профессор Олег Матвейчев считает: «Россия - это антиимпе- 
рия, так как империи высасывают все из колоний, а Россия, наоборот, высасывала себя ради развития “колоний”» [Матвейчев, 2007: 197].

Под русификацией нередко скрывался не “колониализм”, а объективная потребность модерного общества, складывающегося в единое экономическое и культурное пространство. Русский язык проникал в иноязычную среду не только в результате искусственного навязывания, но и потому, что знание государственного языка, являющегося одним из мировых, открывал более широкие жизненные перспективы. В дореволюционной и советской мысли понятие нации имело социальнокультурологическую, а не политическую интерпретацию, в отличие от Западной Европы, где в период Нового времени под нацией понималась гражданская солидарность и народ как источник власти.

Восточные славяне были бы сметены потоком истории, если бы не обладали военной организаций, включавшей в себя всех взрослых мужчин. Исключительно уязвимое геополитическое положение, соседство со Степью превращали интересы обороны в абсолютный приоритет государственной политики. Война стала нормой существования страны, а её милитаризация - отличительной особенностью российской матрицы. Если для Западной Европы был характерен принцип найма на военную службу, то для России - принцип повинности, долга для каждого, прежде всего, элиты, обязанной служить с поместных и вотчинных земель. При Петре I Россия стала первой страной в мире, которая ввела рекрутскую повинность, а затем и всеобщую систематическую воинскую повинность - в 1874 году.

Oсобое значение в государственной системе имели органы политического сыска - тайной полиции, выступающей инструментом контроля верховной власти над элитой и населением - опричнина в эпоху Ивана Грозного, Тайный приказ в царствование Алексея Михайловича, фискалат и прокуратура в период Петра I, Третье отделение собственной Его Императорского Величества канцелярии, Департамент полиции и охранные отделения в XIX - начале XX века, органы ОГПУ-НКВД-КГБ в советское время. "Силовые структуры сами становились объектом борьбы между верховной властью и правящим слоем; перевес той или иной стороны во внутриэлитном противостоянии определялся, как правило, контролем над репрессивным аппаратом” [Гаман-Голутвина, 2006: 418-419], - замечает Оксана Гаман-Голутвина.

Россия на протяжении пяти последних столетий неизменно входила в десятку крупнейших экономик мира. Исключение составили только периоды Крушений Смута, Гражданская война, 1990-е, - когда она скатывалась во второй десяток. При этом страна неизменно отставала от ведущих держав своего времени по качественным хозяйственным параметрам, технологиям, уровню жизни. В России институт частной собственности, составлявший квинтэссенцию западного общества, не мог сложиться в полной мере. Купеческое сословие оставалось весьма замкнутым и сильно зависело от милостей власти. Низкая производительность сельского хозяйства в России, да ещё с учётом того, что до половины крестьянства в течение почти четырех веков находилось в крепостной зависимости, не позволяло сельскому хозяйству рождать капитализм, как в Англии или США.

Роль государства в регулировании экономики неизменно была велика. Широкое распространение получило государственное предпринимательство, которое развивалось параллельно с централизацией власти и переходом под её контроль всё большего объёма земельной собственности. Частное богатство рассматривалось как следствие правительственной милости и на деле часто являлось таковым.

Дух свободного предпринимательства и практики бизнеса отставали от западных. Торговля слишком долго тяготела к натуральному товарообмену. Зарубежный капитал играл внутри России неизменно большую роль, чем российский за грани- 
цей. Весьма неразвитой во все времена оставалась банковская система, отсутствовал доступный кредит. Отличительной чертой является отсутствие нормальной транспортной инфраструктуры.

Распространённое убеждение о “тьме власти” в России, о существовании во все времена необъятного бюрократического аппарата является недоразумением. Чиновничий корпус был - относительно общей численности населения, а уж тем более размера территории - всегда меньше, чем в странах Запада или Востока, и гораздо дешевле обходился казне. У последнего обстоятельства была и обратная сторона: необеспеченность чиновников была одной из причин взяточничества. Коррупция действительно была масштабной и доходила до высоких правительственных сфер.

В России - даже на пике демографической активности - всегда проявлялось несоответствие между относительно небольшой численностью населения и колоссальными размерами территории, протяжённостью границ, масштабами требовавших освоения пространств, неразвитостью поселенческой сети. Немногочисленность бюрократии при столь большой территории предопределила и слабость вертикали власти: в уездах, волостях, не говоря уже о сельских поселениях, представителей центральной власти веками не видали. Но как же тогда управлялась страна? Помещиком, который управлял своими крепостными и чинил над ним суд. Но в крепостной зависимости находилось меньше половины крестьян, и даже там, где крепостное право существовало, помещика могли не видеть вообще. А ответ в том, что в России веками существовало сельское самоуправление.

Крестьянский мир имел самые широкие полномочия возможности решения всех общинных проблем на основе обычного права. Определяющее слово оставалось за главами семейств. Жизнь в мире не гарантировала гармонии - и в деревнях кипели страсти, - но она предполагала поиск согласия во имя общего блага. Западное сознание рассматривает конкуренцию, конфликт как определённую ценность. Для российского сознания ценностью была скорее бесконфликтность. "В мире жить - с миром жить” [Даль, 2012: 148], - гласит русская поговорка. Русская деревня не знала института частной крестьянской, индивидуальной или семейно-дворовой собственности на землю. Земля воспринималось как принадлежащая Господу, а не человеку. Крестьянин пользовался наделом, предоставленном общиной, которая на всем протяжении своего существования вплоть до образования колхозов с 1930-е годы - сохранила принцип периодического уравнительного передела [Сказкин, 1973; Яхшиян, 2013].

Однако в России личность вовсе не растворялась в социуме, как это происходило на Востоке. Народу всегда была присуща тяга к индивидуализации, желание человека “быть о себе”. Ещё византийские источники отмечали свободолюбие славян, склонность расходиться друг с другом во мнении и обнаруживать взаимную страстную неуступчивость (сочинения Маврикия, Прокопия XI века). Во все времена люди сбрасывали тягло - “постылое тягло на мир полегло" - и уходили "на волю”, в степи и леса. Отсюда множество “людей вольных, гулящих”, людей без оседлости, без собственного хозяйства.

Российское сознание расходится с западным в трактовке свободы и справедливости. На Западе свобода - это реализация прав в сочетании с обязанностями, а справедливость является синонимом законности. В России свобода - воля, отсутствие ответственности; справедливость - равенство для всех и сильное патерналистское государство. Идея естественных прав человека практически не существовала в отделенном от государства виде. Если на Западе, в идеальном виде, права и свободы следовало защищать от государства, то в российской традиции права даровались государственной властью, которая и должна была их защищать. 
Россиянам свойственна самоироничная отстраненность. Александр Герцен называл одним из свойств русского духа "способность время от времени сосредоточиться в самом себе, отречься от своего прошлого, посмотреть на него с глубокой, искренней, неумолимой иронией, имея мужество сказать об этом открыто, без цинизма... и без лицемерия, обвиняющего себя, чтобы получить оправдание от других" [Герцен, 1975: 27].

Русская православная церковь во все времена выступала фактором государственного единства, играла огромную роль в сохранении национальной идентичности, выступала культурным стержнем, идейным столпом сопротивления агрессорам. Если для западной матрицы характерно разделение государства и церкви и соперничество между ними, а восточное государство часто основывалось не теократическом принципе, то в православии царь рассматривался как помазанник Божий, но без восточного обожествления, а власть традиционно имела примат над церковью. Русскому православию не были известны те доктринальные конфликты, которые привели к возникновению множества течений в католичестве. С Петра I и до перестройки Михаила Горбачёва РПЦ находилась в абсолютно подчинённом положении у власти: фактически на правах одного из правительственных ведомств в императорской России и гонимой и жёстко преследуемой организации в официально атеистическом Советском Союзе. Существовало сильное антирелигиозное течение в российской элите и интеллигенции, пропитанной идеями позитивизма и социализма. Народ в значительной степени был не столько религиозен, сколько мистичен, вера связывалась не с богословскими познаниями, а с обрядностью.

Притеснения иноверных, гонения на еретиков и даже преследования старообрядцев имели куда меньшие масштабы, чем в Западной Европы. Россия не знала религиозных войн. Сохранялись и сохраняются другие христианские деноминации, традиционными религиями являются ислам, буддизм, иудаизм. Гонения на них, если случались, носили не столько религиозный, сколько политических характер, и по масштабам нередко уступали гонениям на Русскую Православную церковь (особенно, в советское время).

Российский образованный класс в значительно большей степени, чем на Западе, был далек от остального народа, отличаясь даже по одежде и языку. Кроме того, не существовало связи между образованностью и состоятельностью, интеллектуал порой жил бедно и испытывал антибуржуазные чувства. Если западный интеллектуал предлагал продукт своего труда и пытался на нем заработать, пытаясь использовать государство в своих целях, то русский интеллигент искал справедливости и работал на ослабление или свержение любой власти. На все времена справедливы характеристики авторов "Вех", данные русской интеллигенции: оторванность от жизни, прекраснодушие, самомнение, неприятие инакомыслия, отвлеченный догматизм, героический максимализм, историческая нетерпимость, отсутствие чувства связи с прошлым страны.

Отношение к внешнему миру было весьма сложным. Он воспринимался, прежде всего, как источник угроз, от которых спасала сильная армия. Но при этом иноземцев опасались, и особую осторожность проявляли в вопросах веры. У них многое перенимали, но заимствование носило специфический характер. Юрий Пивоваров отмечал, что природа российской власти “предполагает" заимствования, и, прежде всего, того, чего в русской жизни нет вообще. Но заимствования функциональные, а не субстанциальные" [Пивоваров, 2006: 116-117]. Россия заимствовала порядки, как правило, у своего самого сильного противника. Многое было позаимствовано у Византии и монголов. Пётр I перенимал шведскую государственную модель, Александр I - французскую военную модель. Форму организации хозяй- 
ственной жизни Советская Россия заимствовала у соперника в Первой мировой войне - Германии. Либеральную государственную и экономическую модель Россия заимствовала главного противника в “холодной войне" - США. Во всех случаях перенятые за рубежом схемы в России работали хуже, нежели оригиналы.

Была ли Россия частью Западной политической системы? На протяжении большей части своей истории - безусловно нет. Границы Запада с рубежа I-II тысячелетий определялись распространением католицизма, латыни и франкской знати. Вместе с тем, Русь, Россия была крупным государством в Европе, играла важную роль на восточной периферии Западного мира, не раз становилась объектом устремлений включить её в этот мир.

Мой анализ заставляет скорее согласиться с Александром Пушкиным и Александром Герценом, Арнольдом Тойнби и Самуэлем Хантингтоном, которые склонны были видеть в России и её ближайших окрестностях самостоятельную цивилизацию. Специфика России очевидна. Историческое движение страны, раскинувшейся на огромных просторах Евразии от Балтики до Тихого океана, не могло не придать ей специфические черты. Интересный ответ на вопрос об идентичности России дал бывший глава французского МИДа Юбер Ведрин: “Глядя из Франции, я не понимаю, почему Россия вечно задаётся вопросом: Европа она или Азия? её место однозначно посередине, не обязательно в качестве моста, но непременно в качестве одного из крупных полюсов этого мира" [Ведрин, 2011: 178].

Российскость можно понять, прежде всего, исходя из собственной сущности самой России, а не чьей-то ещё. Россия - самодостаточный культурноцивилизационный феномен, который может быть описан только в её собственных терминах. "Россия - это огромный, целостный и уникальный мир со своим генетическим кодом истории, системой архетипов социальности, культуры, духовности, особым способом их проживания в истории и самой истории, со своим типом локально-цивилизационного бытия и развития" [Козин, 2012: 523], - справедливо, на мой взгляд, пишет философ Николай Козин. Россия не является ни западной частью Востока, ни восточной частью Запада. Это стержневое государство самостоятельной цивилизации, назовём ли мы её российской или восточноевропейской, к которой европейская цивилизация наиболее близка.

\section{Список литературы}

Ахиезер А., Клямкин И., Яковенко И. (2005) История России: конец или новое начало? М.

Баталов Э. (2002) Политическая культура России через призму civic culture // Pro et Contra. №3. Лето 2002. С. 17.

Бердяев Н. (1990) Истоки и смысл русского коммунизма. М. С. 8.

Бродель Ф. (2008) Грамматика цивилизации. М. С. 502.

Ведрин Ю. (2011) "Место России однозначно посередине" // Россия в глобальной политике. Ноябрь-декабрь 2011. С. 178.

Гаман-Голутвина О. (2006) Политические элиты России: Вехи исторической эволюции. М. С. $418-419$.

Герцен А. (1975) Собрание сочинений. Т. 8. М. С. 27.

Гоголь Н.В. (1952) Избранные места из переписки с друзьями // Николай Гоголь. Полное собрание сочинений. Т. 8. М. С. 308.

Даль В. (2012) Избранные пословицы русского народа. М. С. 148.

Ильин И. (1992) Наши задачи. Исторические судьбы и будущее России. Т. 1. М. С. 285.

Ильин И. (1992) Наши задачи на чужбине. Историческая судьба и будущее России. Т. 1, М. С. 327.

Клаузевиц. 1812 год. (1937) М. С. 93-94, 92.

Ключевский В. (1987) Курс русской истории. Т. 1. М. С. 312.

Козин Н. (2012) Россия. Что это? М. С. 523.

Матвейчев О. (2007) Суверенитет духа. М. С. 197. 
Пивоваров Ю. (2006) Русская политика в её историческом и культурном отношениях. М. С. 17, 116-117.

Размышления о России и русских. Штрихи к истории русского национального характера (1996) / Сост. С.К. Иванова. М. С. 124.

Сказкин С.Д. (1973) Избранные труды по истории. М. С. 64-65; Яхшиян О.Ю. (2013) Крестьянская община и самоуправление в России // Российская государственность: исторические традиции и вызовы ХХІ века. М.

Солженицын А. (1998) Россия в обвале. М. С. 112.

Тойнби А.Д. (2009) Исследование истории. Возникновение, рост и распад цивилизаций. Т. 1. М. C. 182.

\section{References}

Ahiezer A., Kljamkin I., Jakovenko I. (2005) Istorija Rossii: konec ili novoe nachalo? M.

Batalov Je. (2002) Politicheskaja kul'tura Rossii cherez prizmu civic culture // Pro et Contra. №3. Leto 2002. S. 17.

Berdjaev N. (1990) Istoki i smysl russkogo kommunizma. M. S. 8.

Brodel' F. (2008) Grammatika civilizacii. M. S. 502.

Dal' V. (2012) Izbrannye poslovicy russkogo naroda. M. S. 148.

Gaman-Golutvina O. (2006) Politicheskie jelity Rossii: Vehi istoricheskoj jevoljucii. M. S. 418-419.

Gercen A. (1975) Sobranie sochinenij. T. 8. M. S. 27.

Gogol' N.V. (1952) Izbrannye mesta iz perepiski s druz'jami // Nikolaj Gogol'. Polnoe sobranie sochinenij. T. 8. M. S. 308.

Il'in I. (1992) Nashi zadachi. Istoricheskie sud'by i budushhee Rossii. T. 1. M. S. 285.

Il'in I. (1992) Nashi zadachi na chuzhbine. Istoricheskaja sud'ba i budushhee Rossii. T. 1, M. S. 327.

Klauzevic. 1812 god. (1937) M. S. 93-94, 92.

Kljuchevskij V. (1987) Kurs russkoj istorii. T. 1. M. S. 312.

Kozin N. (2012) Rossija. Chto jeto? M. S. 523.

Matvejchev O. (2007) Suverenitet duha. M. S. 197.

Pivovarov Ju. (2006) Russkaja politika v ejo istoricheskom i kul'turnom otnoshenijah. M. S. 17, 116-117.

Razmyshlenija o Rossii i russkih. Shtrihi k istorii russkogo nacional'nogo haraktera (1996) / Sost. S.K. Ivanova. M. S. 124.

Skazkin S.D. (1973) Izbrannye trudy po istorii. M. S. 64-65; Jahshijan O.Ju. (2013) Krest'janskaja obshhina i samoupravlenie v Rossii // Rossijskaja gosudarstvennost': istoricheskie tradicii i vyzovy XXI veka. M.

Solzhenicyn A. (1998) Rossija v obvale. M. S. 112.

Tojnbi A.D. (2009) Issledovanie istorii. Vozniknovenie, rost i raspad civilizacij. T. 1. M. S. 182.

Vedrin Ju. (2011) "Mesto Rossii odnoznachno poseredine" // Rossija v global'noj politike. Nojabr'dekabr' 2011. S. 178.

\section{Russian matrix}

Author. Nikonov, Vyacheslav. Doctor of historical Sciences, professor, Dean of the faculty of public administration of Moscow state University. Address: 1, Leninskie Gory, Moscow, 119991, Russia. E-mail: ieras@mail.ru

Abstract. The article analyzes the historical development of Russia in the context of two approaches. The first approach relies on such traits of the Russian character and statehood, as collegiality, teamwork, "autocracy, Orthodoxy and nationality", natural democracy. The second approach considers Russia through the prism of concepts such as organic authoritarianism, Imperial dictatorship, the omnipotence of the state and the injustice of society.

The author concludes that Russia is an independent civilization, and the specificity of Russia is obvious. Russia is self-sufficient cultural and civilizational phenomenon that can only be described in its own terms. This is a phenomenon with its system of archetypes sociality, culture, spirituality, in a special way their stay at the history and the story itself, with its type locally-civilizational existence and development. The author concludes that Russia is neither Western part of the East nor of the Eastern part of the West. This rod the independent state of civilization, whether we call it Russian or Eastern European, to which European civilization is closest.

Keywords: civilization, Russia, Russian culture, European civilization, democracy, collectivism. 